\title{
III. On a new and simple heliostat
}

\section{R. Potter Jun. Esq.}

To cite this article: R. Potter Jun. Esq. (1833) III. On a new and simple heliostat, Philosophical Magazine Series 3, 2:7, 6-8, DOI: 10.1080/14786443308647956

To link to this article: http://dx.doi.org/10.1080/14786443308647956

$$
\text { 曲 Published online: } 01 \text { Jun } 2009 .
$$

Submit your article to this journal $\square$

Цll Article views: 2

Q View related articles $₫$ 
By means of these data we obtain for the total magnetic intensity at the beginning of the present year 1832,-

$\begin{array}{ccccc}\text { Paris. } & \text { Brussels. } & \text { Göttingen. } & \text { Berlin. } & \text { Stockholm. } \\ 1.0000 & 10205 & 1.0010 & 0.9982 & 1.034 .0\end{array}$

The result for Berlin differs greatly from that which might have been expected from the general decrease of the intensity with the latitude. I have no reason, however, to suppose that there is any error in the observations. The dip was determined by four trials, as well by myself alone, as by M. Riess and me; and the differences between the results were extremely small.

Stockholm, Sept. 20th, 1832.

III. On a Nero and Simple Heliostat. By R. Potter, Esq., Jun.* [With Figures: Plate I.]

HAVING a short, time ago determined upon commencing a series of optical experiments, which will require the use of an instrument having the effect of a heliostat, my first step was to seek to make myself acquainted with the principle of that of Dr. S'Gravesande. This is the only instrument of the kind of which I have yet met with any account; and, by accident, the work which I consulted for a description of it having the plates bound in a separate volume, I could only at that time have access to the description without the plate.

Those who know Dr. S'Gravesande's instrument will not be surprised that I should soon be embarrassed in consulting a description intended only to be intelligible with the assistance of the figures. I had not, however, got through the account, when a thought struck me that the simplest plan of a heliostat must be on the equatorial principle: another moment's reflection convinced me that a very simple, yet effective construction might be adopted upon that method.

I have since made a heliostat upon this plan; and having proved its efficacy, I now proceed to give a description of it. The instrument I have executed is similar to figures 2 . and 3 , of which fig. 2. represents the side view, and fig. 3. the horizontal one. Before, however, we go to the description of the instrument itself, we will examine the principle of its construction.

Let $e o$, fig. I. be a spindle which can be made to revolre, and which is set parallel to the earth's axis. Let $a b$ be a mirror attached to the end of the spindle. Then the appa-

* Communicated by the Author. 
rent daily motion of the sun being nearly in a circle round the earth's axis, and sensibly also in a circle round the spindle $e o$, if the mirror be so set as to reflect the sun's light in the direction $o p$, still parallel to the earth's axis, and if the spindle revolve, with the mirror, once round in twenty-four hours, then whilst the sun continues to shine on the mirror, its light will be reflected in the same direction $o p$. The truth of this will be easily seen on considering that the positions of the sun and the mirror must be the same at all times of the day with respect to the line $o p$; and to an eye placed at $p$, the reflected image of the sun would appear to stand still, and hence the propriety of the appellation Heliostat.

For the source of motion to the spindle, $I$ have used a common clock, shown at $f g$, fig. 3 , and $f g h$, fig. 2 ; the whole apparatus being attached to a rectangular board, as seen in the figures. The hands of the clock being removed, a grooved pulley is fixed on the arbor, which had carried the hour-hand, as at $i$, fig. 3. This pulley revolving once round in twelve hours when the clock is going, communicates motion by means of a band to the pulley $k$, fixed on the spindle $e o$, which being twice the diameter of the pulley $i$, causes the spindle to revolve, as required, once in twenty-four hours.

The band which I have found to answer well for the pulleys is a strong cotton thread passed several times round them, and then fastened with a loop, which leaves the means of adjusting the band to a proper tightness. The pendulum should be adjusted by the revolution of the spindle after the instrument is complete, by which means any slipping of the band, or want of accuracy in the dimensions of the pulleys, may be compensated.

Considerable care is requisite to keep this, as well as every other instrument of a similar kind, correctly in position; for it will readily be perceived that the correct action of it depends as much upon the spindle $e o$ being accurately placed, as upon the proper rate of the clock. I have had mine so nearly adjusted, as to reflect the sun's light upon the same spot on the ceiling of a lofty room so exactly, that no perceptible motion could be detected during an hour and a half.

It will be seen that neither this nor.Dr. S'Gravesande's heliostat has any provision for counteracting the variation of the sun's declination during the time of use, and of course the instruments may be brought to act more correctly when the sun is near the summer or winter solstice than at other times of the year.

If an instrument-maker were employed to construct this heliostat, he would easily contrive the plan so as to connect 
the spindle and clock into one whole, and so as to dispense with the band and pulleys: he would also see where to introduce the proper contrivances for adjusting the various parts.

This instrument may certainly be executed at much less expense than that of Dr. S'Gravesande, and I think it will be much more easily and correctly adjusted. It should be always provided with a second mirror, as at $l m$, fig. 2 , by which the pencil of light may be thrown in any direction which may be desirable: in many optical experiments, however, the second mirror will be unnecessary.

\section{Of the Structure of Living Fabrics. By the Rev. Patrick Keith, F.L.S.*}

THE structure of every living fabric is composed partly of solids, and partly of fluids. The solids are the substances which constitute the several parts or organs that give form to the fabric, as the head, feet, limbs and trunk of animals; or the root, trunk, leaves, and flowers of vegetables. The fluids are substances absorbed or imbibed from without, or formed, secreted, or exhaled from within,-as chyle, blood, lymph, urine,-sap, nectar, cambium, expressed juice. While life remains the fluids are in motion, except in the very singular case of the hybernation of some animals, and perhaps of some plants; or in the equally singular case of some very vivacious animalcula, which, though left on the stage of the microscope till they have shrunk, by the evaporation of the fluid in which they were placed, to a mere dry and shrivelled-up membrane, will again revive and move as at first, upon the application of a little fresh water. The same thing happens to many of the mosses, which will revive and recover their verdure when moistened with water, even after having been completely dried, and kept in a dried state, for many years.

The perfection of the individual is in the ratio of the complexity of its organization. The fewer the organs, the fewer the faculties with which the individual is endowed. This is very evident even on the most superficial survey of the grand divisions of the empire of animated nature. Look at any individual, or at any group of individuals, belonging to the vegetable kingdom. Where are the organs of locomotion; where are the organs of sense? They are organs of which the vegetable is altogether destitute. Look at any individual, or at any group of individuals, belonging to the animal king$\mathrm{dom}$, and the organs of sense and of locomotion are the first

* Communicated by the Author. 

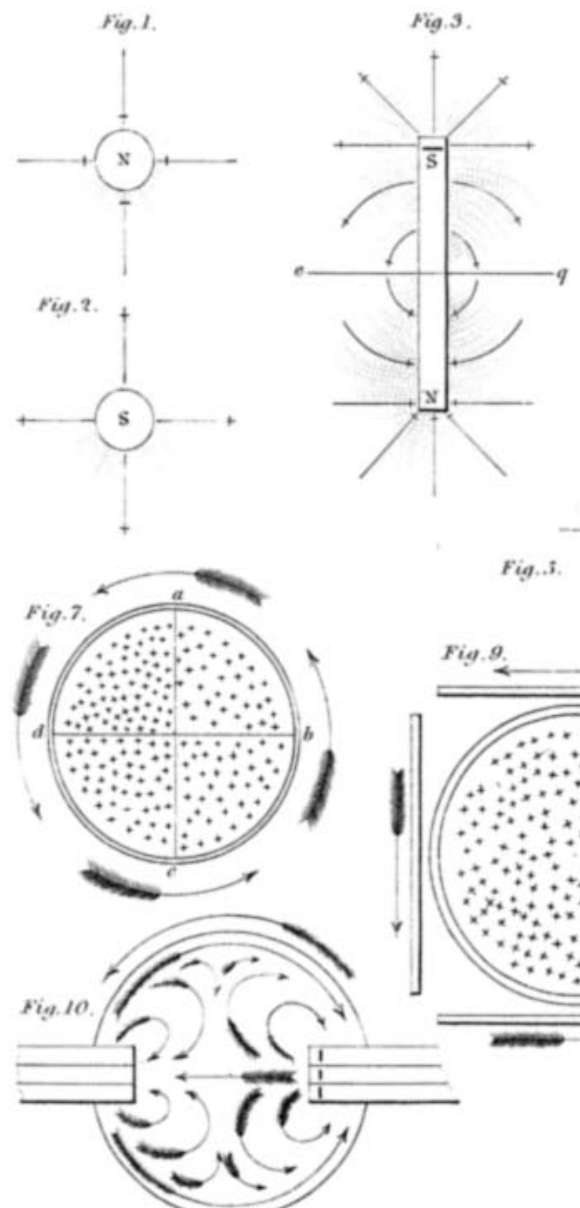

Fig. 9 .

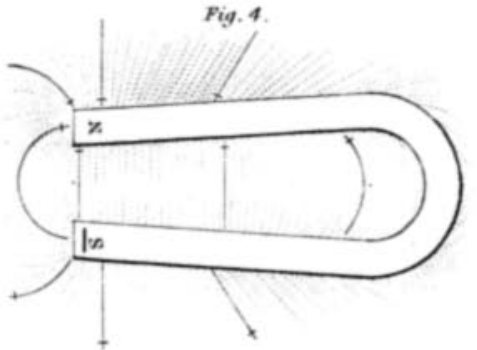

Fig. 6.

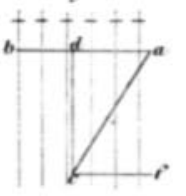

Fig...
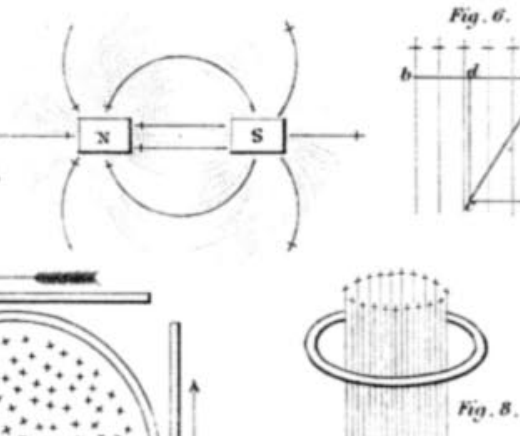

rig. 8 .

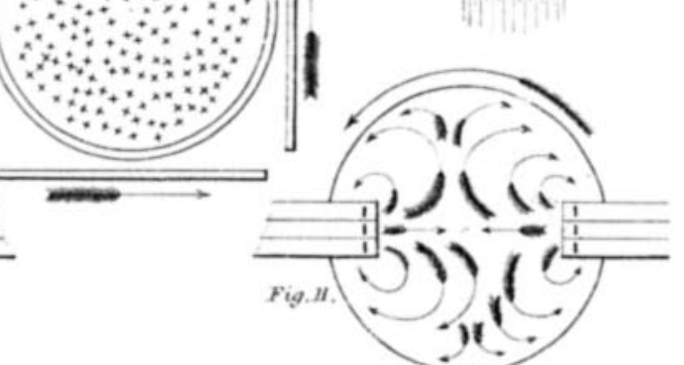

Al. Shergeons Theory of Magnedic OPedricily.

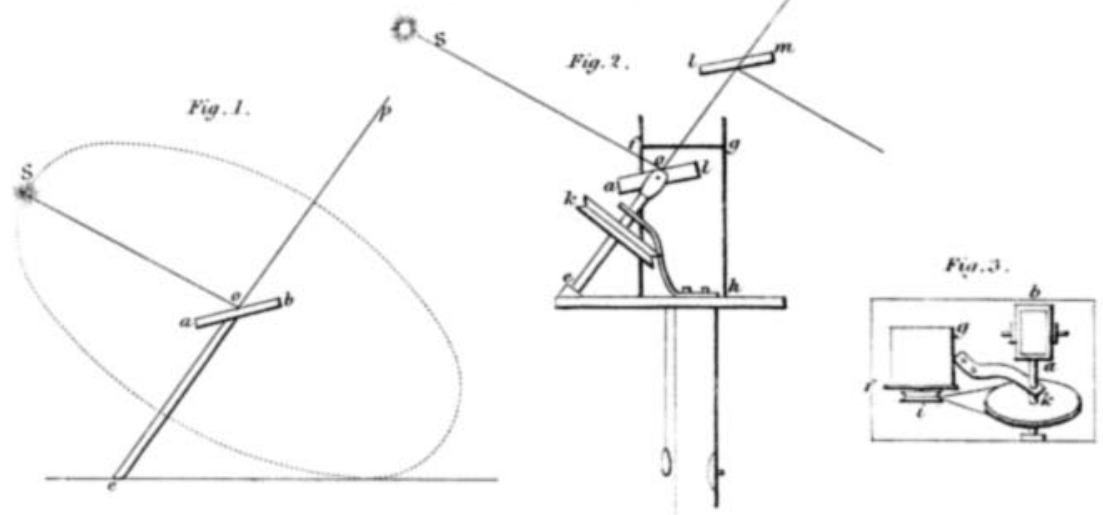

ell: Pollers new Hetiostats 